щей разрешение спора, происходящего из контракта, в какомлибо международном арбитраже означает волеизъявление сторон переместить разбирательство на международный уровень, за пределы какой-либо национальной юрисдикции. В этом случае арбитры прежде всего должны выявить выраженную или подразумеваемую волю сторон, чтобы решить коллизионную проблему, присущую подобному разбирательству, и определить материальное право, применимое к контракту. Если это не удается, арбитр, решая еx bono et aeguo, должен определить применимое право, которое наиболее подходит к контракту, принимая во внимание объективные условия и особые обстоятельства дела.

Статья поступила в редакцию в декабре 1998 г.

\title{
ПРОБЛЕМЫ СИСТЕМАТИЗАЦИИ РОССИЙСКОГО ЗАКОНОДАТЕЛЬСТВА О МЕЖДУНАРОДНОМ ЧАСТНОМ ПРАВЕ
}

\author{
A.A. $\mathrm{K}$ a 3 a $\mathrm{K}$ O $\mathrm{B}^{*}$
}

В современньх условиях дальнейшее обеспечение интеграции России в Мировую систему хозяйственных связей, участие в. процессе международного разделения труда, активное привлечение иностранньх инвестиций, увеличение объемов участия российских субъектов права в мировом частноправовом обороте становится крайне затруднительньм без наличия в российском праве развитой системы правового регулирования международных частноправовых отношений.

Проблемы систематизашии норм международного частного права исследовались разными поколениями отечественньх кристов. Уже в 20-е годы была начата разработка советской системы норм МЧП (например, см. Плоткин М.А. Об общесоюзной советской системе норм Международного Частного Права//М.: Мехдународное Право, 1928. - № 1. - с. 96-101).

* Слушатель Российской школы частного права при Президенте РФ, начальник юридического управления Балашихинской Торгово-Промыпленной Палаты. 
В 1989-90-х годах ВНИИ Советского государственного строительства и законодательства подготовил проект Закона о Международном частном праве и международном грахданском процессе. В дальнейшем вопрос о систематизации постоянно обсуждался доктриной.

Однако разработка подобной системы осложнена целым рядом трудностей. Отметим лишь некоторые из них:

1) В правовой науке нет единой точки зрения о состоянии и правовой природе норм МЧП, следовательно встает вопрос, а что, собственно говоря, систематизировать?

2) Какой из известных способов систематизации предпочесть?

3) Пожалуй, самое сложное - юридически корректно и непротиворечиво сформулировать нормы МЧП с учетом требований российской правовой традиции, с одной стороны, требований, предъявляемьх общественными отношениями (в первую очередь, торгово-экономическими) к регулированию отношений с иностранным элементом на современном этапе развития общества и научно-технического прогресса, с другой стороны, а также по возможности учесть мехдународньй опыт в этой области.

В настоящее время практически завершена разработка раздела VII части 3-й Гражданского Кодекса Российской Федерации: опубликован проект этой части (см. Российская газета от 30 октября 1996 г.). Невозможно не оценить работу, проделанную авторами Проекта.

Однако следует отметить, что временное угасание интереса законодателя к вопросу систематизации норм МЧП, наблюдаемое сегодня, дает российской правовой мысли еще один шанс "свежим взглядом" оценить уже проделанную работу, внести необходимые коррективы и дополнения.

\section{Общетеоретические вопросы систематизации норм международного частного права}

При рассмотрении вопроса о теоретических основах систематизации норм международного частного права, а также при проведении практической работы в этой области непременно встағот две основньх проблемы:

- определить предмет систематизации, т.е. что, какие действующие нормы приводить в определенную систему, и

- каким образом систематизировать отобранные нормы.

Для удобства обозначим эти две проблемы как предмет систематизации и метод систематизации.

Предмет систематизации

При проведении систематизации в области международного 
частного права в первую очередь необходимо определить, что должно войти в систему МЧП, нашедшую свое отражение в неком нормативном акте (для удобства назовем этот акт ЗакоHOM)?

Ответ, что Закон о Международном Частном Праве должен объединить все нормы МЧП, не представляется удовлетворительным по ряду причин.

Во-первых, В правовой науке нет единой точки зрения о составе и правовой природе норм МЧП.

Традиционное понимание этой проблемы относит к нормам МЧП лишь коллизионные нормы внутреннего происхождения. Указанной концепции придерживаются Г.К. Матвеев, А.Б. Левитин. Известный немецкий ученый Лео Раапе в своем труде "Международное Частное Право" отмечает, что "источником МЧП является лишь закон и обычай. Международные договоры, как двухсторонние, так и групповые (многосторонние), например, Гаагские конвенции по межпународному частному праву, служат лишь опосредованньм источником МЧП. Они (международные договоры - прим. автора) связывают граждан заключившего договор государства, лишь если последнее превращает эти договоры в закон" (11, с. 27-28). Из этого можно сделать вывод, что коллизионные нормы, независимо от их изначального происхождения, находят свое закрепление лишь посредством национального закона и/или обычая, следовательно и система МЧП состоит в итоге лишь из коллизионных норм внутреннего происхождения.

Наравне с этой теорией существует предположение о том, что МЧП включает коллизионные нормы как внутреннего, так и внешнего происхождения. Этого мнения придерживаются такие ученые, как С.Н. Лебедев, А.И. Минаков.

И если С.Н. Лебедев признает себя вынужденным согласиться с некоторыми оговорками с мнением Л. Раапе (Лебедев С.Н. К вопросу о природе Мехдународного Частного Права.//М.: Советский ежегодник международного права за 1979 год. - 1980. С. 61-80), то А.И. Минаков уже подвергает так называемую теорию "трансформации" детальной критике (Минаков А.И. Международньй договор как источник Международного Частного Права (вопросы теории)//М.: Советский ежегодник международного права за 1986 год. - 1987. - С. 228-241), справедливо замечая, что признание лишь внутренней природы норм МЧП "выхолашивает сущность Международного Частного Права" (с. 241).

Наряду с указанными концепциями существует теория, согласно которой МЧП состоит как из коллизионньх норм, так и 
из материально-правовьх норм внутреннего происхождения, специально предназначенных для регулирования грахданскоправового оборота, отягощенного иностранным элементом. Впервые данную теорию развили в 1940 году И.С. Перетерский и С.Б. Крылов в своем учебнике Международного Частного Права. Против такого понимания природы норм международного частного права активно выступал Лазарь Адольфович Лунц, отмечая, что по всякому отношению с иностранным элементом возникает коллизионный вопрос и отнесение материально-правовых норм внутреннего права к системе МЧП стерло бы всякую разницу между ним (МЧП) и гражданским правом. Он же совместно с М.И. Брагинским и Г.К. Матвеевой активно участвовал в формировании теории, согласно которой МЧП включает в себя как коллизионные нормы, так и унифицированные материальноправовые нормы. Следует отметить, что эта теория подвергается в последнее время все большей критике со стороны М.М. Богуславского (7, с. $97-98$; с. 180$)$.

Для целей настоящей статьи важно то, что несмотря на разницу подходов подавляющее большинство юристов сходятся на том, что коллизионные нормы являются частью МЧП. Соответственно, разумно предположить, что Закон о МЧП должен включить в себя по крайней мере коллизионные нормы, т.е. нормы, отсылаґщие к тем или иным материально-правовым нормам.

Следует также отметить, что как на практике, так и в теории возникает необходимость в урегулировании применения иностранного права (применение которого вполне может быть обусловлено конкретной коллизионной нормой). Проблемы квалификации (первичной и вторичной), обратной отсылки и отсылки к третьему и последующим правопорядкам, взаимности, реторсий, публичного порядка, обхода закона, классически относимые $\mathrm{K}$ общей части системы международного частного права, требуют законодательного разрешения.

Учитывая современное развитие правовой мысли и опыт зарубежньх стран в кодификации норм МЧП, можно сделать вывод о том, что национальный Закон о МЧП должен содержать:

1) в общей части - нормы о квалификации, обратной отсылке и отсылке к третьему и последуюшим правопорядкам, взаимности, реторсиях, публичном порядке, соотношении норм Закона о МЧП и правил международных договоров. Уже упоминавшийся нами правовед-международник М.А. Плоткин предлагал внести еще и норму об "экстерриториальности действия советского (теперь уже российского) закона", что в сложившихся в 20-е годы условиях всеобщего отказа от применения советского права 
(даже при наличии отсылки к нему) было в высшей степени оправдано. В современньх условиях вокруг проблемы экстерриториального действия национального законодательства идут жесткие дискуссии. Особенно показателен здесь опьт США, считающих экстерриториальность ключевым принципом правового регулирования, имеюшим своей целью расширение пространственной сферы действия внутренних нормативньгх актов США. Мы считаем, что включение общей нормы об экстерриториальном действии российского права в целом в Закон о МЧП недопустимо ввиду противоречия данной нормы основным принципам международного публичного права о суверенитете государств и невмешательстве во внутренние дела. Отметим также, что в самих США большая часть норм об экстерриториальном действии американского права находится в составе отраслевого законодательства (в основном - экспортного), а не в Своде законов о конфликте законов и Своде законов о праве мехдународньх отношений;

2) в особенной части - коллизионные нормы внутреннего происхождения.

Включение же в Закон о МЧП внутренних материально-правовьх норм, предназначенньх для регулирования гражданскоправовьх, семейных и трудовых отношений с иностранным элементом, едва ли оправдано в силу большето объема таких норм и их постоянного изменения, что не может способствовать установлению стабильности Закона о МЧП, с одной стороны, с другой стороны включение в Закон о МЧП указанных внутренних материально-правовьх норм пойдет вразрез с мировой и отечественной практикой материально-правового регулирования отношений с иностранным элементом путем издания отдельньгх актов (см., например Закон РСФСР об иностранных инвестициях в РСФСР от 04.07.1991 г., Кодекс Международной Торговли ЧССР, Закон о международных хозяйственньх договорах КНР, Инвестиционные Кодексы и законы о передаче технологий ряда развивающихся стран и пр.).

При рассмотрении вопроса о предмете Закона о МЧП необходимо также учесть критику самой идеи систематизации норм МЧП в едином источнике. Один из критиков идеи какой-либо систематизации - В.А. Гридин утверждает, что практически невозможно в одном законодательном акте объединить все действующие коллизионные нормы, и что за рамками такого акта неизбежно останется определенное число таких норм "специального” назначения. Например, коллизионные нормы в области торгового мореплавания, кредитно-расчетньх отношений.

Действительно, объединить абсолютно все действующие в 
стране коллизионные нормы в едином акте если не теоретически, то практически невозможно. Да и стоит ли к этому стремиться? Пожалуй, нет. Основная цель подобного акта - объединить коллизионные нормы, имеющие наибольшее значение, а также нормы так называемой "общей” части МЧП, оставив отраслевому законодательству регулировать специальные отношения.

метод систематизации

До этого момента мы намеренно пьтались избежать употребления термина "кодификация" норм МЧП, применяя вместо него термин "систематизация", имеющий, как это известно, более широкое значение. Систематизация подразумевает упорядочение нормативньх актов в целях обеспечения удобства пользования ими на практике. Теория права различает три основньх вида систематизации: инкорпорация, консолидация и кодификация.

Из приведенньх выпше трех видов кодификация представляет собой наиболее сложную и совершенную форму систематизации, направленную на коренную - как внешнюю, так и внутреннюю - переработку действуюшего законодательства. Формами кодификации являются основы, кодексы, уставы, положения и т.п. Независимо от названия все они представляют собой органические законы, в которьх объединены различные правовые нормы, институты, регламентирующие отношения в рамках определенной правовой отрасли.

Консолидация же является специфическим видом систематизации законодательства. Ее цель - устранение множественности нормативньх актов, их унификация и создание в структуре законодательства крупньх однородньх блоков (но не отдельньх актов!). Консолидация выступает в качестве важнейшего звена между правотворчеством и кодификацией.

В.И. Кисель (см. Кисель В.И. Правовая реформа в СССР и некоторые аспекты Международного Частного Права // М.: Советское Государство и Право, 1990. - № 1. - С. 98-105) также отмечает, что кодификация норм мехдународного частного права возможна следуюшими тремя путями:

1) в различных разделах общего материально-правового акта (например - Франция);

2) в отдельньх разделах отраслевых законодательных актов (например, разделы грахданских и семейньх кодексов - Греция, Испания, Портуталия, Аргентина, СССР). По этому же пути идут авторы Проекта;

3) в едином специализированном законе (Венгрия, ФРГ, Польша, Чехия, Югославия, Швейцария, Турция).

За исключением того, что термин "кодификация" применим 
лишь к третьему пункту перечня, позиция В.И. Киселя представляется правильной.

Необходимо заметить, что консолидация норм МЧП в отдельных разделах отраслевьх законодательных актов в странах континентальной Европы рассматривается как переходный этап к качественно более высокому уровню - кодификационному акту. Такова, например, позиция профессора Альфреда фон Овербека (Alfred E. von Overbeck).

В плане выбора пути систематизации представляет интерес опьт ГДР, где долгое время действовало Германское Гражданское Уложение 1896 г. с соответствующими изменениями и поправками. Когда обсуждалась возможность кодификации норм гражданского и семейного права встал вопрос о судьбе коллизионных норм. Часть разработчиков предложила следовать традиции и включить в Гражданский и Семейный кодексы соответствующие разделы. Друтие предлагали разработать самостоятельный акт. При подтотовке Семейного кодекса учли первое предложение. Однако в дальнейшем после обработки опыта этой кодификации, на основе более глубокого изучения тенденций развития МЧП и его национальньх кодификаций пошли по второму пути, включив в кодификационный акт коллизионные нормы гражданских, семейньх и трудовьх отношений.

Советская и российская правовая мысль на протяжении всего времени обсуждения вопроса о систематизации норм МЧП также склонялась к принятию единого кодификащионного акта. Ярьм сторонником этого подхода является О.Н. Садиков. В пользу проведение кодификации норм МЧП, заключающейся, как уже было указано, в коренной переработке действующего законодательства, свидетельствует и процесс усложнения структуры самой коллизионной нормы. По мнению профессора О.Н. Садикова, появление третьего элемента в структуре коллизионной нормы гипотезы, обусловило появление так называемых дополнительных, или субсидиарных коллизионньх норм $(16$, с. $205-219)$. "Усложнение в новейших источниках системы коллизионньх норм проявляется также и в том, что для многих гражданско-правовьх институтов предусматривается главная (основная) коллизионная привязка, а затем формулируются специальные (дополнительные) коллизионные привязки, применяемые для решения конкретньх вопросов, которые могут возникать в рамках данного института... Примером является использование общей и специальной коллизионньх привязок для определения сферы действия обязательственного статута" (16, с. 211$)$.

Сложно отрицать и необходимость в современных условиях подробного коллизионного регулирования новых правовых ин- 
ститутов (прежде всего многочисленные разновидности подряда - геологоразведочные работы, проектирование, монтаж, а также различные формы передачи технологий - лицензионное соглашение, франшизное соглашение, традиционное соглашение на право испољљзования товарного знака и т.д.).

Указанные проблемы практически невозможно решить простой консолидацией норм МЧП. Коренное, качественно новое переосмысление действующего законодательства, его не только внешняя, но и внутренняя переработка возможны только в отдельном кодификационном акте, которьй, кстати, даже по своему объему значительно превысит те сорок статей, вошедших на сегодняшний день в текст Проекта.

$\mathrm{K}$ сожалению, при решении вопроса о методе систематизации разработчики Проекта не учитывают ни достижений российской и зарубежной юридической мысли, ни опњ на новейших кодификаций норм МЧП, ни современного уровня развития МЧП, следуя по пути Основ Гражданского Законодапельства Союза ССР и Республик 1991 г. Соответственно, в случае принятия Проекта в настоящей редакции можно будет констатировать, что задача кодификации российского законодатепства о МЧП остается нерешенной. Таким образом и вопрос о создании российской системы международного частного права остается открытым: Проект являет собой лишь очередной шаг в этой области.

\section{Некоторые вопросы общей части Проекта}

Как уже отмечалось выше, возникает необходимость в урегулировании самого применения иностранного права. Проблемы квалификации, обратной отсылки и отсылки к третьему и последуюшим правопорядкам, взаимности, реторсий, публичного порядка, обхода закона прежде всего требуют законодательного разрешения. Это признается и практикой систематизации норм МЧП. Уже кодекс Бустаманте 1928 г. (5), хотя он и не является национатьной кодификацией норм МЧП, все же содержит во вступительном разделе некоторые нормы, касающиеся квапификации (ст. 6 кодекса Бустаманте), международного публичного порядка - т.е. норм, одинаково обязываюших всех, находящихся на территории данного государства (ст. 8 кодекса Бустаманте). Однако некорректно будет умолчать, что часть рассматриваемьх нами норм находятся и в других частях кодекса Бустаманте. Например, норма о квалификации и классификации имуцеств (ст. 113 кодекса Бустаманте).

Первый раздел системы коллизионного права М.А. Плоткина включает нормы о пределах экстерриториального действия советского права, принятия обратной ссылки, публичном порядке. 
Учитьвая же доктрину и опыт современньх иностранньх кодификаций (общая часть Закона о МЧП Венгрии, СФРЮ, и пр.), авторы Проекта включили рассматриваемые нами нормы в отдельную главу.

Раздел 1 Проблемы квалификации (ст. 1224 Проекта).

Вопросы квалификации традиционно считаются одними из наиболее сложных как в теории, так и в практике МЧП. В своих работах Л.А. Лунц указывает, что "применение коллизионной нормы требует надлежашего разрешения вопроса о порядке ее толкования" (Лунц Л.А. К вопросу о "квалификации" в Международном Частном Праве // М.: Советский ежегодник международного права за 1979 год. - 1980. - С. 212-220). Анализ действуюших ныне Основ обнаруживает практически полный пробел по вопросу о квалификации (исключение составляет ст. 165 Основ, устанавливаюшая, что место совершения сделки определяется по советскому праву). Отдельной статьи, посвященной квалификации, в Основах нет. Решение вопроса квалификаџии и стало одной из первоочередньх задач авторов Проекта.

Как известно, “объем" коллизионной нормы и ее "привязка" обозначаются терминами и соответствующими понятиями, далеко не всегда совпадающими в разшичньх правовьх системах (даже в рамках одной правовой семьи можно наблюдать различное, а иногда и прямо противоположное понимание того или иного термина. Так, облитации корпораций, не имеюшие какого-либо конкретного обеспечения, носят в США название debentures. В Великобритании значение этого слова прямо противоположное: облигации с обеспечением. Соответственно проблему квапификации можно разделить на две части - квалификацию понятий "объема" и квалификацию понятий "привязки".

Что касается квалификапии понятий, содержашихся в "привязке" колтизионной нормы, то этот вопрос можно считать решенньм: необходима квалификация по закону суда. Данная концепция давно получила подтверждение в отечественной доктрине.

Сложнее дело обстоит с квалификацией понятий, содержашихся в "объеме" коллизионной нормы. Самым простым вариантом решения проблемы и здесь будет квалификаџия по закону суда (именно по этому пути пошли авторы Проекта). Эта теория также господствует в литературе и судебной практике на Западе.

Однако данная теория имеет многочисленньх противников как в России, так и за рубежом: М. Вольф (квалификация по lex causae), Э. Рабель (теория автономной Квалификашии) резко выступали против квалификации по закону суда. Можно также констатировать, что подавляощее большинство советских юристов склонны к автономной квалификации понятий “объема" 
коллизионной нормы. Однако трудно представить, как на практике суд или арбитраж будут квалифицировать понятия “объема" путем обобщения цивилистических понятий различных правовых систем. На Западе справедливо отмечается, что нельзя требовать от суда знания и применения методов сравнительного правоведения.

Возможно, исходя из соображений практики, правы авторы Проекта, применившие, с одной стороны, привычный и наиболее удобный способ квалификации по lex fori, а с другой стороны, указав исключения из данного принципа (п. 2 ст. 1224 Проекта), которые позволят суду применять иностранное право в случае необходимости при отсутствии или несовпадении соответствующих понятий в российском праве, невозможности толкования этих понятий по российскому праву). Отметим, что подобный подход наблюдается и в Законе о МЧП Венгрии.

Все сказанное выше является лишь кратким изложением некоторых соображений автора, касающихся наиболее общих вопросов дальнейшего развития отечественной системы международного частного права. Подводя итоги, еще раз отметим предпочтительность принятия отдельного нормативно-правового акта, целиком посвященного регулированию системы МЧП, лишь с принятием которого действительно можно будет говорить о создании российской системы международного частного права.

Отметим также, что несмотря на то, что автор разделяет взгляды И.С. Перетерского, С.Б. Крылова и М.М. Богуславского, согласно которым в систему МЧП входят не только коллизионные и унифицированные нормы, но и внутренние материальноправовые нормы, регулирующие отношения с иностранным элементом, Закон о МЧП (либо любой иной источник, систематизирующий нормы МЧП) должен избежать включения указанных материально-правовьх норм. Сфера его (Закона) действия - разрешение вопросов коллизии права. По мнению автора, в идеале российский Закон о МЧП должен содержать:

1) в общей части - нормы о сфере действия Закона, квалификации, применении права страны с множественностью правовьх систем, установлении содержания иностранного права, взаимности, публичном порядке, общее правило о неприменении иностранного публичного права (в особенности - иностран ных карательных законов и иностранного налогового законодательства), оговорку о возможности применения так называемьх "сверхимперативньх" норм (например, норм о национализации), обратной отсылке и отсылке К третьему и последуюшим правопорядкам, взаимности и реторсиях;

2) в особенной части - главы о лицах (физических и юриди- 
ческих), о браке и разводе (включая нормы об определении происхождения, алиментньх обязательствах, опеке и попечительстве), имуцествах и способах приобретения собственности, об обязательствах и договорах, о наследовании.

Cтатья поступила в редакцию в сентябре 1998 а.

\section{РОССИЙСКИЕ ВЛАСТИ, РОССИЙСКИЕ ИНВЕСТОРЫ, БЕРИТЕ ПРИМЕР!}

В Англии продана национальная святыня британцев, гордость нации - стадион "Уэмбли", с которым связано много знаменательньх событий в истории английского футбола. В частности, именно на нем сборная Англии более двадцати лет назад стала чемпионом мира.

Стадион продан всего за \$172,2 млн. Купил его консорциум футбольной ассоциации Англии. В то же время американская компания SFX Entertaiment предлагала за эту историческую реликвию в два с лишним раза больше - $\$ 352$ млн.

Акционеры компании, владевшей стадионом, мотивировали свой поступок тем, что эта спортивная арена "должна оставаться английской”. Сооруженная в 1923 году, она обветшала, и на ее восстановлением потребуется $\$ 380 \mathrm{млн,} \mathrm{которые} \mathrm{новый} \mathrm{собст-}$ венник собирается получить от всеанглийской лотереи.

А затем в 2006 году Англия хочет получить право на проведение чемпионата мира, открытие и финал которого состоятся, конечно, на обновленном "Уэмбли”. Кроме Англии за это право борются Бразилия, Германия, Гана, Египет, Марокко, Нигерия и ЮАР. В ходе предварительньх переговоров англичане призвали ЮАР отказаться от борьбы за ЧМ - 2006 в пользу Англии, за что, по сообщению ИТАР-ТАСС, англичане поддержат ЮАР в проведении ЧМ - 2010, но южноафриканцы категорически отказались. 